Research Paper

\title{
An oral quinoline derivative, MPTOB392, causes leukemic cells mitotic arrest and overcomes drug resistant cancer cells
}

\author{
Min-Wu Chao ${ }^{1}$, Han-Li Huang ${ }^{1}$, Wei-Chun HuangFu ${ }^{1}$, Kai-Cheng Hsu ${ }^{1}$, Yi-Min Liu ${ }^{2}$, \\ Yi-Wen Wu ${ }^{3}$, Chao-Feng Lin ${ }^{1}$, Yi-Lin Chen ${ }^{1}$, Mei-Jung Lai ${ }^{4}$, Hsueh-Yun Lee ${ }^{2}$, Jing- \\ Ping Liou', Che-Ming Teng ${ }^{2,5}$, Chia-Ron Yang ${ }^{3}$ \\ ${ }^{1}$ The Program for Cancer Biology and Drug Discovery, College of Medical Science and Technology, Taipei Medical University, \\ Taipei 11031, Taiwan \\ ${ }^{2}$ School of Pharmacy, College of Pharmacy, Taipei Medical University, Taipei 11031, Taiwan \\ ${ }^{3}$ School of Pharmacy, College of Medicine, National Taiwan University, Taipei 10051, Taiwan \\ ${ }^{4}$ Translational Research Center, Taipei Medical University, Taipei 11031, Taiwan \\ ${ }^{5}$ Pharmacological Institute, College of Medicine, National Taiwan University, Taipei 10051, Taiwan
}

Correspondence to: Chia-Ron Yang, email: cryang@ntu.edu.tw

Keywords: MPTOB392, mitotic arrest, drug resistance, acute leukemia

Received: July 25, $2016 \quad$ Accepted: January 23, $2017 \quad$ Published: February 06, 2017

Copyright: Chao et al. This is an open-access article distributed under the terms of the Creative Commons Attribution License (CC-BY), which permits unrestricted use, distribution, and reproduction in any medium, provided the original author and source are credited.

\section{ABSTRACT}

Despite great advances in the treatment of acute leukemia, a renaissance of current chemotherapy needs to be improved. The present study elucidates the underlying mechanism of a new synthetic quinoline derivative, MPTOB392 (B392) against acute leukemia and its potential anticancer effect in drug resistant cells. B392 caused mitotic arrest and ultimately led to apoptosis. It was further demonstrated to be a novel microtubule-depolymerizing agent. The effects of oral administration of B392 showed relative potent anti-leukemia activity in an in vivo xenograft model. Further investigation revealed that B392 triggered induction of the mitotic arrest, followed by mitochondrial membrane potential loss and caspases cleavage by activation of $\mathrm{c}$-Jun $\mathbf{N}$-terminal kinase (JNK). In addition, B392 enhanced the cytotoxicity of sirolimus in sirolimusresistant acute leukemic cells through inhibition of Akt/mTOR pathway and Mcl-1 protein expression, and also was active in the p-glycoprotein ( $p$-gp)-overexpressing National Cancer Institute/Adriamycin-Resistant cells with little susceptibility to p-gp. Taken together, B392 has potential as an oral mitotic drug and adjunct treatment for drug resistant cancer cells.

\section{INTRODUCTION}

Current therapy for most types of acute leukemia consists of traditional chemotherapy, including microtubule-targeting agents (MTA) such as vincristine [1-4]. MTA have been used for decades in a majority of malignancies, including prostate cancer, ovarian cancer, breast cancer, non-small lung cancer, and hematological malignances [5], and they continue to produce impressive clinical outcomes. Despite their reputation as oldfashioned drugs, many MTA have been developed and tested in ongoing clinical trials [6].

Resistance to chemotherapy has been an essential issue in current cancer treatment over the past cascades. The mechanisms of chemotherapeutic resistance, which can be divided into intrinsic and acquired, vary in different types or stages of cancers. Tumor cell-specific over-activated pathways and p-glycoprotein (p-gp) overexpression are the most common drug-resistance mechanisms in chemotherapy [7]. P-glycoprotein, a family member of ATP-binding cassette (ABC) transporters, pumps out its substrate, such as vincristine or paclitaxel, to decrease the concentrations of drugs within the cells, and which plays an essential role in MTA-caused drug resistance [8].

The mammalian target of rapamycin (mTOR), a key serine/theonine kinase, regulates various cellular processes required for protein synthesis, growth, and cell cycle progression and metabolism [9]. Genetic mutations, over-activated tyrosine kinase receptors, and amplification of key factors in PI3K/AKT pathways have been identified to lead to abnormal activation of mTOR signaling in leukemia [10]. Thus, mTOR inhibitors were investigated in preclinical and clinical antitumor studies, 
such as leukemia, lymphoma, endometrial carcinoma, renal carcinoma, breast cancer and glioblastoma [11].

Quinoline derivatives possess many diverse biological activities, including antifungal [12], antimalarial $[13,14]$, and anticancer effects [15-17]. The present study investigates the anticancer effect of a new synthetic quinoline compound, MPT0B392 (B392; 6-methoxy-2(3,4,5-trimethoxy-benzenesulfonyl)-quinolin-5-ylamine), on acute leukemia and drug resistance. We found that B392 inhibited tubulin polymerization and induced c-Jun $\mathrm{N}$-terminal kinase (JNK) activation, leading to apoptosis. More importantly, B392 can be administered orally in an in vivo leukemic cell xenograft model. Additionally, B392 potentiated cytotoxicity in sirolimus (rapamycin)-resistant acute leukemic cells and the multidrug resistant cell line. It was further be demonstrated not a p-gp substrate. The results of the present study suggest that B392, as a developmental drug, could have a potential use in the clinics, especially applied in second line chemotherapy.

\section{RESULTS}

\section{Evaluating the anticancer effect of B392 in leukemic cell lines}

To determine the in vitro antitumor activity of B392 (Figure 1A), we performed an MTT assay in leukemic cell lines. As shown in Figure 1B, B392 inhibited the cell viability of HL60, MOLT-4, and CCRF-CEM cells in a concentration-dependent manner, with $\mathrm{IC}_{50}$ values of 0.02 , 0.03 , and $0.02 \mu \mathrm{M}$, respectively, at $48 \mathrm{~h}$; and it shows better cytotoxic effect than vincristine in primary AML cells (Supplementary Figure 1A). Moreover, B392 caused less sensitivity in normal cells, including BEAS (human bronchial epithelial cells), HUVECs (human umbilical vein endothelial cells) (Figure 1C) and PBMC (peripheral blood mononuclear cell) (Supplementary Figure 1B). To investigate the mechanism underlying the cytotoxicity exhibited by B392, we further evaluated cell cycle progression after treatment with B392. The data show that B392 triggered cells arrest in the G2/M phase, followed by accumulation in subG1 phase in a concentration and time-dependent manner (Figure 1D; Supplementary Figure 2A-2C). In conclusion, B392 displayed more sensitive on leukemic cells than normal cells.

\section{B392 induces apoptosis in xenograft models}

The MOLT-4 and HL60 xenograft model studies were performed to evaluate B392 as a potential anticancer drug for the treatment of leukemia. Figure 2A shows that B392 treatment resulted in significant tumor growth delay $(83.3 \%)$ and tumor volume inhibition $(P<0.01)$ (Figure 2A, 2C), without loss of body weight (Figure 2B, 2D). Here, vincristine treatment group was used to be a positive control to demonstrate the animal studiesy were workable. Moreover, immunochemistry staining and tumor homogenates show that B392 treatment induced apoptosis in cancer cells, demonstrated by detection of positive staining of cleavage caspase 3 (Figure 2E, 2F). Taken together, these data suggest that B392 exhibited anticancer activity with less cytotoxicity both in vitro and in vivo.

\section{The effect of B392 on microtubule dynamics}

Microtubules play an important role in cell mitosis, and administration of microtubule-binding agents usually result in mitotic arrest [5]. Therefore, we used an in vitro tubulin-polymerization assay as well as tubulin staining (observed using confocal microscopy) to assess whether B392 had an effect on tubulin and would lead to cells accumulation in G2/M phase. As seen in Figure 3A, B392 caused tubulin depolymerization in vitro and disrupted microtubule formation, as observed by diffusion of stained tubulin into the cytoplasm, which phenomena was also shown in vincristine treatment. Paclitaxel and vincristine were utilized as positive controls for tubulin polymerization and depolymerization, respectively (Figure 3B).

To clarify the mechanism by which B392 induced G2/M cell cycle arrest in leukemic cells, we observed the expression of $\mathrm{G} 2 / \mathrm{M}$ regulatory proteins. As cells enter mitosis, a variety of proteins are phosphorylated either directly or indirectly by M-phase-promoting factor (MPF) [18]. MPM2, an antibody that can specifically detect the phosphorylation of $\mathrm{M}$ phase regulatory proteins, is often used to differentiate the phase in which cells accumulate (e.g. G2 or M phase). The results show that B392 treatment upregulated intracellular MPM2 and cyclin B1 and downregulated the inhibitory Try-15 residue of Cdk1 (cdc2), indicating that B392 induced cell arrest in M phase. Additionally, increased expression of Aurora A and B (mitotic spindle kinases), which play a role in the regulation of cell division [19] as well as phosphorylation of H3S10, suggested that B392 might activate the mitotic checkpoint (Figure 3C; Supplementary Figure 2D). Our data suggests that B392 is a novel microtubule-destabilizing agent that induces mitotic arrest in leukemic cells.

\section{Evidence of B392-triggered apoptosis}

Mitochondria play a crucial role in cells undergoing the apoptotic process [20]; hence, we further evaluated the expressions of mitochondrial proteins and mitochondrial function, which was assessed by measuring the permeability of their outer membranes. As seen in Figure 4A, B392 caused the phosphorylation of Bcl-2, Mcl-1S (Mcl-1 short form) increase and decrease in Mcl1L (Mcl-1 long form), which provided evidence that mitochondrial membrane potential time-dependently lost in HL60 cells (Figure 4B). Mcl-1S, a splicing variant of the antiapoptotic Mcl-1 (Mcl-1L), is a proapoptotic protein 
[21]. Induction of apoptosis by B392 was elucidated by the observation of a hypodiploid peak (subG1) in leukemic cells (Figure 1D). The activation of caspase 3, 7, 8, 9 and poly (ADP-ribose) polymerase (PARP) cleavage in a time-dependent manner further confirmed B392-induced apoptosis (Figure 4C). These data suggest that B392 has an effect on mitochondrial proteins, membrane potential as well as activation of the classic apoptosis pathway and ultimately cell death.

\section{JNK activation plays a key role in B392-induced apoptosis of leukemic cells}

It has been reported that differential regulation of mitogen-activated protein kinases (MAPKs) is induced by microtubule binding agents $[22,23]$. To further investigate the mechanism of B392-induced cell apoptosis, we analyzed the phosphorylation of JNK, P38, and extracellular signalregulated kinase (ERK) after treatment with B392. The

A<smiles>COc1cc(S(=O)(=O)c2ccc3c(N)c(OC)ccc3n2)cc(OC)c1OC</smiles>

\begin{tabular}{lc}
\hline Cell line & IC50 $(\mu \mathrm{M})$ \\
\hline HL60 & $0.02 \pm 0.04$ \\
MOLT-4 & $0.03 \pm 0.08$ \\
CCRF-CEM & $0.02 \pm 0.05$ \\
\hline
\end{tabular}

B
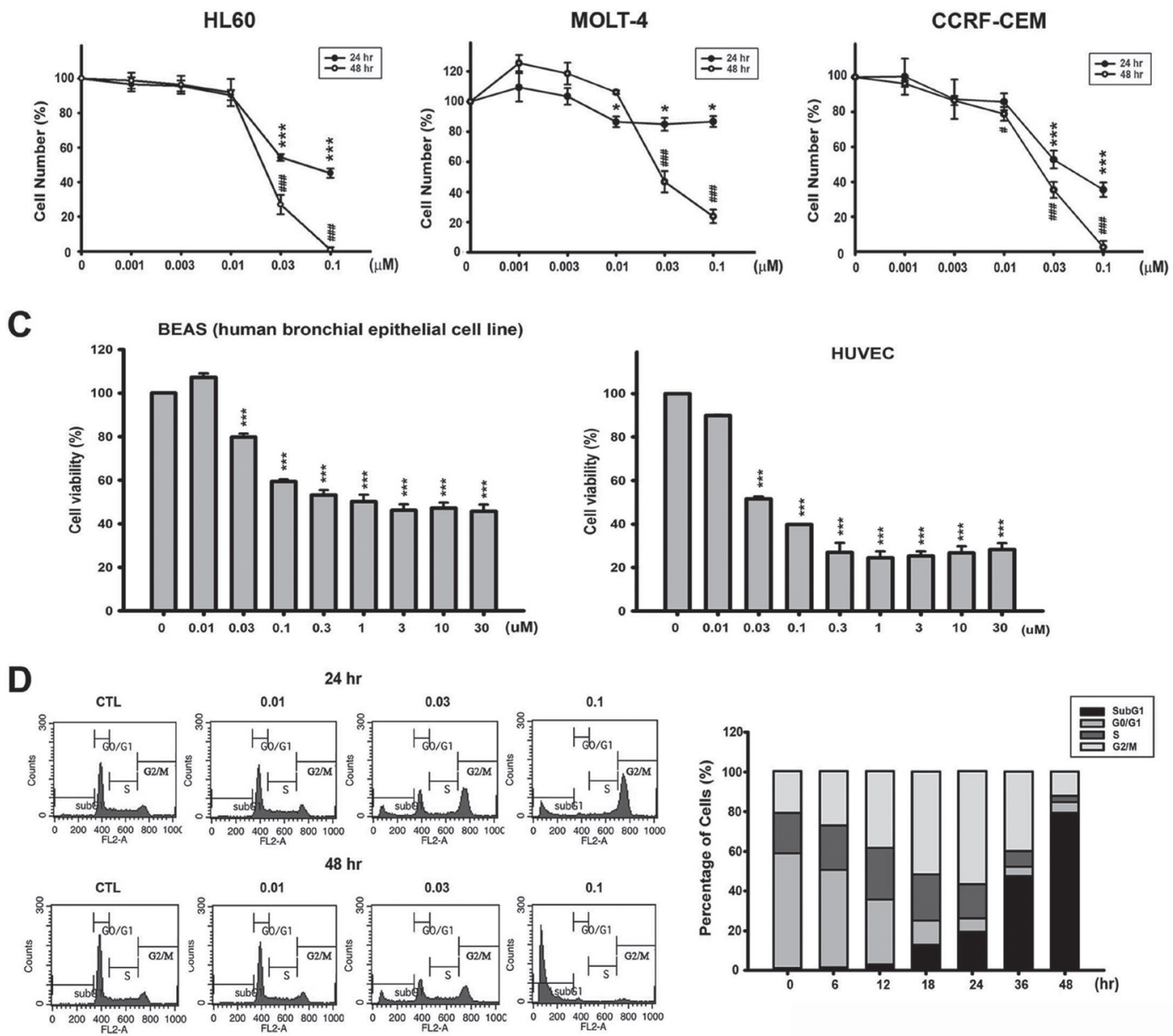

Figure 1: Chemical structure of B392 and its potential anticancer effect in vitro. (A) The chemical structure of B392. (B) Cell viabilities of B392 in HL60 (acute promyelocytic leukemia), MOLT-4 (acute lymphoblastic leukemia), CCRF-CEM (acute lymphoblastic leukemia) and (C) normal cells (BEAS, human bronchial epithelial and HUVEC, human umbilical vein endothelial cell) were determined by MTT assay at $48 \mathrm{~h} .{ }^{*} P<0.05,{ }^{* * *} P<0.001,{ }^{\#} P<0.05,{ }^{\# \#} P<0.001$ compared with the control group. (D) Time (right panel) and concentration-dependent (left panel) of B392 on cell cycle progression. HL60 cells were treated with vesicle (0.1\% DMSO) or 0.01, 0.03, $0.1 \mu \mathrm{M}$ of B392 for 24 and $48 \mathrm{~h}$ (left panel) and treated with vesicle $(0.1 \%$ DMSO) or $0.1 \mu \mathrm{M}$ of B392 for $6,12,18,24,36,48 \mathrm{~h}$ (right panel). Cell cycle distribution was performed by flow cytometry. IC50 values were calculated by sigmoidal dose-response equation and expressed as mean plus minus SD at $48 \mathrm{~h}$ treatment. 
results show that $\mathrm{p}-\mathrm{JNK}$ and p-P38 were induced by B392 in a time-dependent manner, with maximum induction observed at 24 and $36 \mathrm{~h}$ (Figure 5A). We used a p-P38 inhibitor (SB203580) and p-JNK inhibitor (SP600125) to identify the specific MAPK involved in B392-induced cell death. The data on cell cycle distribution revealed that only SP600125 was able to reverse B392-induced subG1 accumulation (Figure 5B, 5C; Supplementary Figure 3) as well as the expressions of mitochondrial proteins ( $\mathrm{p}-\mathrm{Bcl}-2$, and Mcl-1), caspase 3, and PARP (Figure 5D) in HL60 cells. The above observation was not found after co-treatment with SB203580 and B392 (Data not shown).

\section{B}

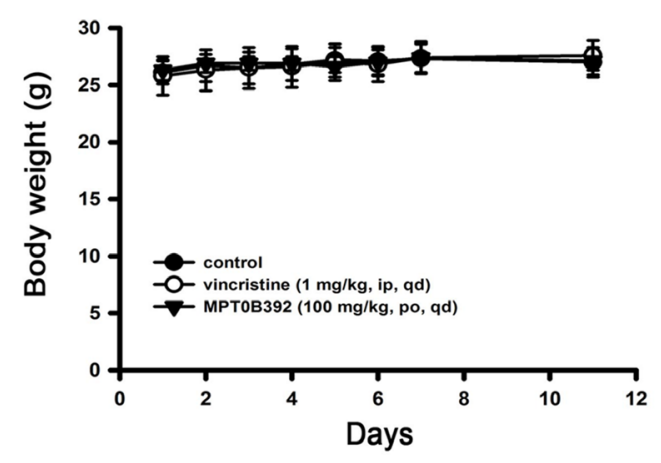

D

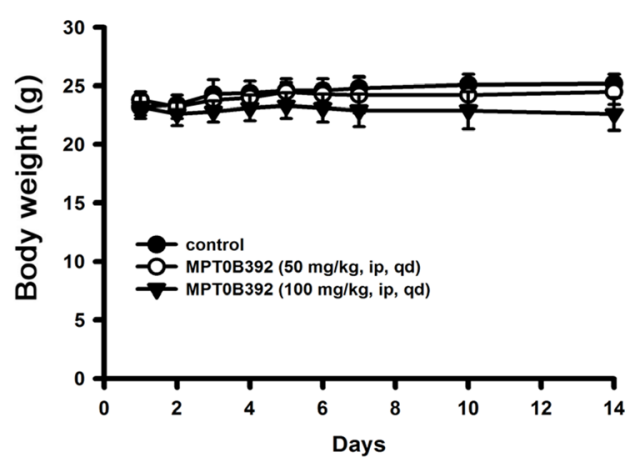

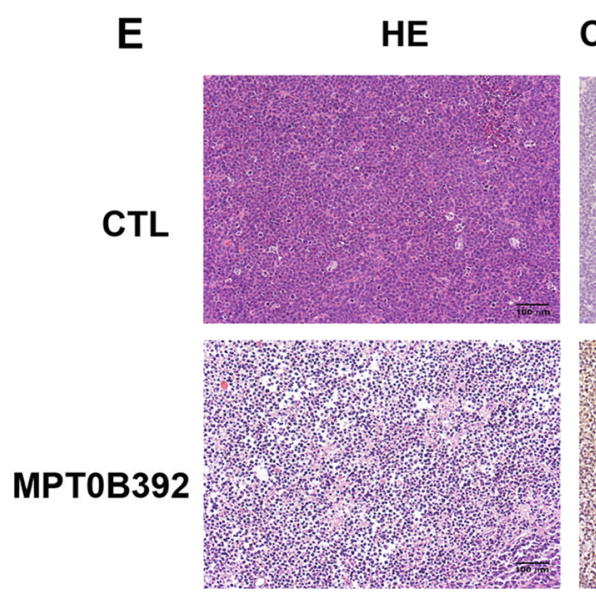
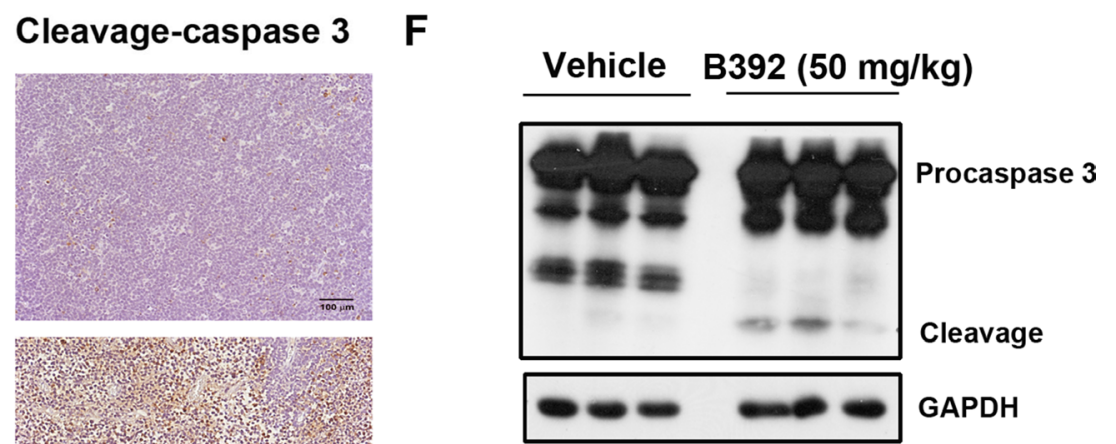

Figure 2: The effect of B392 in MOLT-4 and HL60 xenograft models. SCID mice were ectopically implanted with MOLT-4 cells (A, B) or HL60 cells (C, D). Vincristine $1 \mathrm{mg} / \mathrm{kg}$ (i.p.), B392 $50 \mathrm{mg} / \mathrm{kg}$ or $100 \mathrm{mg} / \mathrm{kg}$ (p.o. or i.p.) were treated. (A and C) The curves show the effect of B392 on tumor volume and percentage of tumor growth delay (TGD), which was calculated for treatment groups relative to control group. (B and D) The body weight of mice after indicated drugs treatment. (E) Immunohistochemical staining for the MOLT-4 tumors' sections. Upper panel is the control, and lower panel is the B392 treatment group. Left panel was stained with hematoxylin and eosin; and right panel with cleavage caspase 3, which represents cells under apoptosis. Each tumor sample is under $160 \times$ magnification. (F) HL60 xenograft tumour homogenates were used to analyse cleavage caspase 3 protein expressions to determine apoptosis. 


\section{B392 enhanced the cytotoxicity of sirolimus in a sirolimus-resistant cell line}

It has been shown that a number of genetic mutations elevate PI3K/AKT/mTOR signaling, and contribute to cell proliferation, survival, and drug resistance in leukemia $[24,25]$. Thus, combining cytotoxic chemotherapy agents could enhance sensitivity to mTOR inhibitors and achieve better outcomes. We first evaluated the baseline sensitivity of sirolimus (rapamycin) in different acute leukemic cells lines via the MTT assay. Figure 6A shows that acute myeloid leukemic cells HL60, MOLM-13, and MV4-11 were more resistant to sirolimus, with $\mathrm{IC}_{50}$ values of 14.02 , 10.38 , and $7.41 \mu \mathrm{M}$, respectively, while comparing with acute lymphoblastic leukemic cells MOLT-4 and CCRF$\mathrm{ECM}\left(\mathrm{IC}_{50}\right.$ values of 0.32 and $0.42 \mu \mathrm{M}$, respectively). In the sirolimus-resistant cell line, HL60, a combination of sirolimus with B392 enhanced the cytotoxicity of sirolimus compared to sirolimus alone; however, this phenomenon was not observed in the sirolimus-sensitive cell line, MOLT-4 (Figure 6B; Supplementary Table 1). The combination of B392 and sirolimus clearly induced PARP and caspase 3 cleavage, as well as downregulated a key prosurvival protein, Mcl-1 (Figure 6C, left panel). The effect of a sirolimus-B392 combination on $\mathrm{AKT} / \mathrm{mTOR}$ signaling was also determined. B392 alone only had a slight effect on the AKT/mTOR pathway; however, the combination dramatically decreased the expression of p-AKT and p-mTOR, as well as mTOR's downstream targets, p-P70S6K and p-4EBP1 (Figure 6C, right panel). Taken together, B392 can strengthen the effect of sirolimus on mTOR signaling and can enhance cytotoxicity in sirolimus-resistant acute myeloid leukemia (AML) cells.

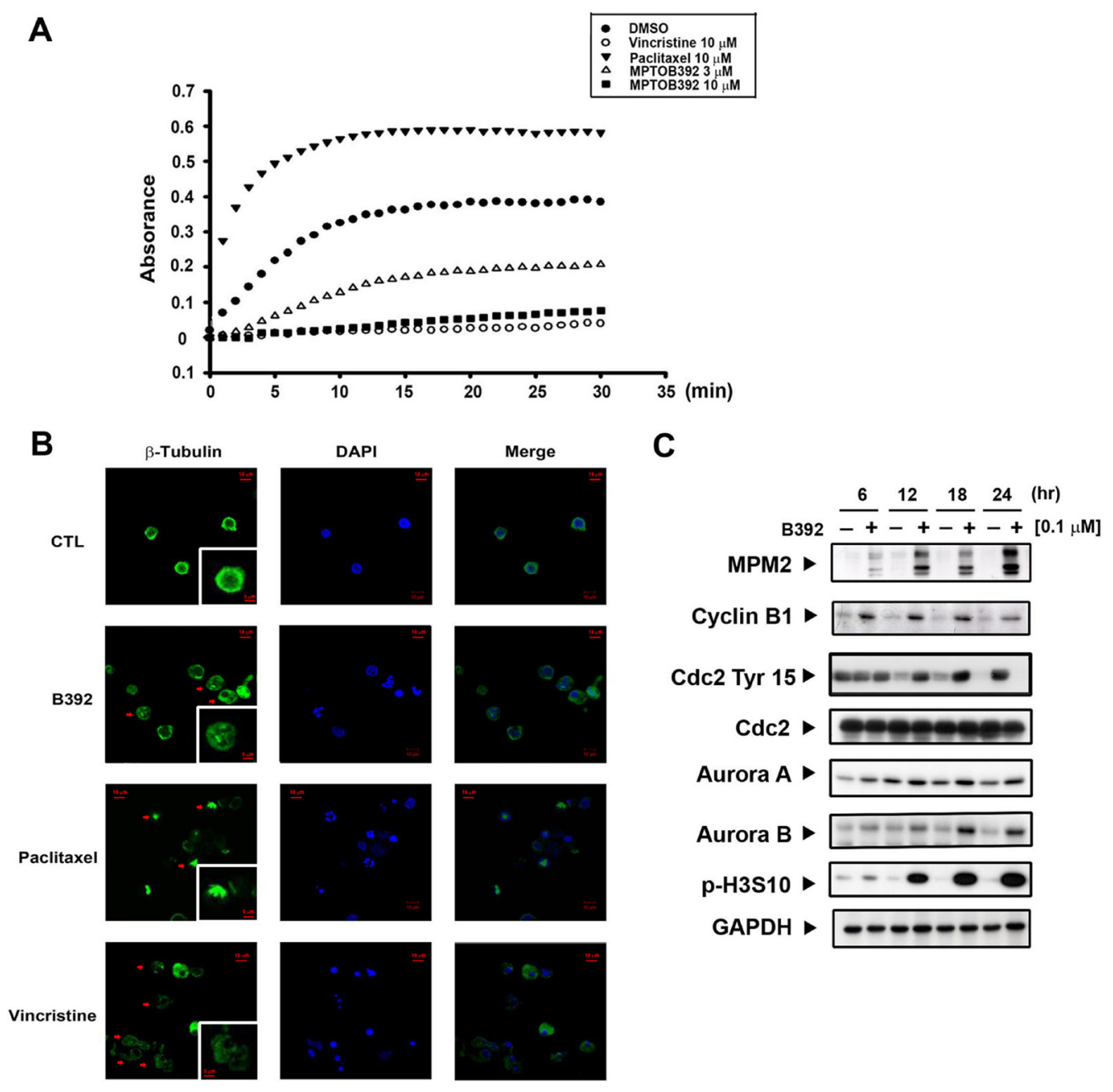

Figure 3: B392 is a depolymerizing agent and caused mitotic arrest. (A) In vitro tubulin polymerization assay was performed to evaluate the effect of $\mathrm{B} 392$ on microtubule dynamics. In cell-free condition, tubulin proteins were in reaction buffer in the presence or absence of B392 $(3$ or $10 \mu \mathrm{M})$, paclitaxel $(10 \mu \mathrm{M})$ or vincristine $(10 \mu \mathrm{M})$. Assembly of microtubules was determined by measuring absorbance at $340 \mathrm{~nm}$. (B) HL60 cells were exposed to $0.1 \mu \mathrm{M}$ B392, $10 \mu \mathrm{M}$ vincristine and $10 \mu \mathrm{M}$ paclitaxel for $24 \mathrm{~h}$. The changes of microtubule network were visualized by staining $\beta$-tubulin as arrows indicated. Nuclear DNA was stained by DAPI. $10 \mu \mathrm{M}$ vincristine and $10 \mu \mathrm{M}$ paclitaxel were used as positive controls for tubulin depolymerization and tubulin polymerization, respectively. (C) HL60 cells were treated $0.1 \mu \mathrm{M}$ B392 time-dependently to detect the expressions of G2/M related proteins. 


\section{Multiple drug resistance cell line was sensitive to B392, which was not a p-gp substrate}

The p-gp multidrug transporter, a broad ATPdependent efflux pump, can export a variety of natural products and microtubule-binding agents, including vincristine and paclitaxel, from the cell; it reduces the efficacy of anticancer drugs and is often regarded as a major mechanism for drug resistance. Figure 7A shows that p-gp-overexpressed NCI/ADR-RES cell was more sensitive to B392 than to vincristine or paclitaxel. Additionally, we investigated the susceptibility of B392 to

A

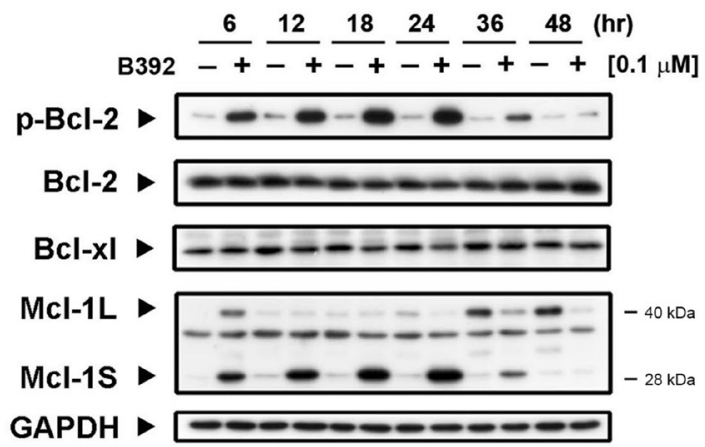

B

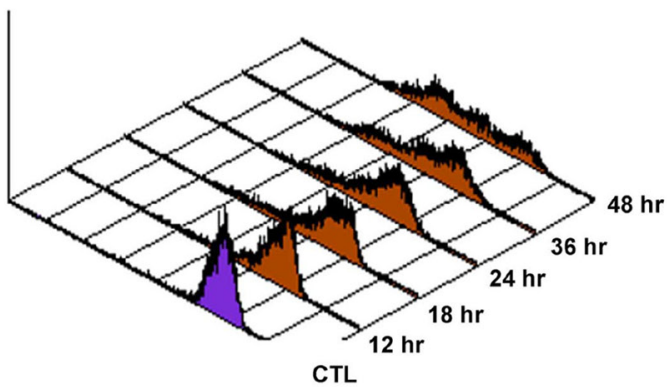

C

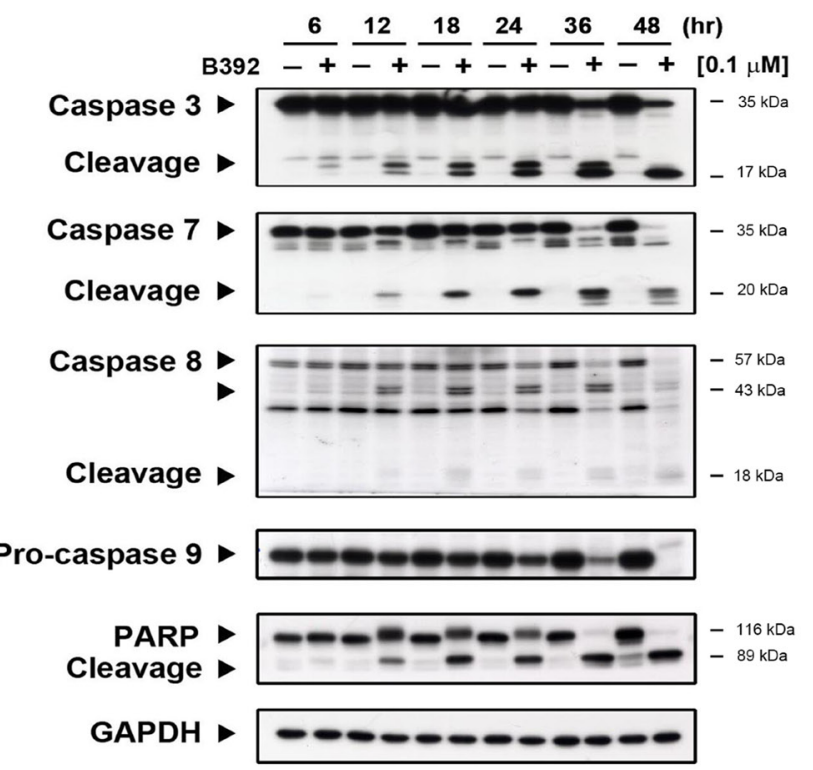

Figure 4: The effect of B392 on apoptosis. (A) HL60 cells were treated with $0.1 \mu \mathrm{M} \mathrm{B392}$ for indicated time then were harvested for detection of p-Bcl-2, Bcl-xl, Bcl-2, and Mcl-1 by western blot analysis. (B) The phenomena of mitochondria potential loss was measured by flow cytometry analysis with rhodamine-123. HL60 cells were treated with B392 $(0.1 \mu \mathrm{M})$ for indicated time and then incubated with rhodamine-123 $(10 \mu \mathrm{M})$ at $37^{\circ} \mathrm{C}$ for $30 \mathrm{~min}$. The horizontal axis shows the relative fluorescence intensity, when the right curve shift to the left cure represents a loss of mitochondrial membrane potential. (C) HL60 cells were treated with vehicle $(0.1 \%$ DMSO) or B392 $(0.1 \mu \mathrm{M})$ for indicated times. The expressions of cleavage caspases and PARP were detected by western blot analysis. GAPDH used as an internal control. 
A

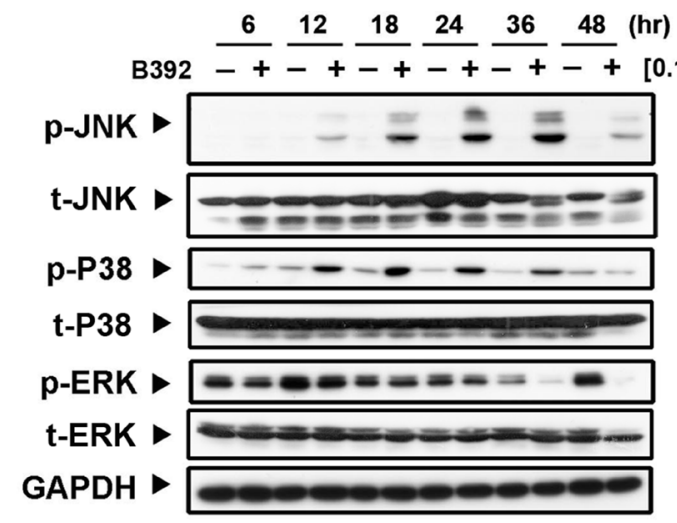

B
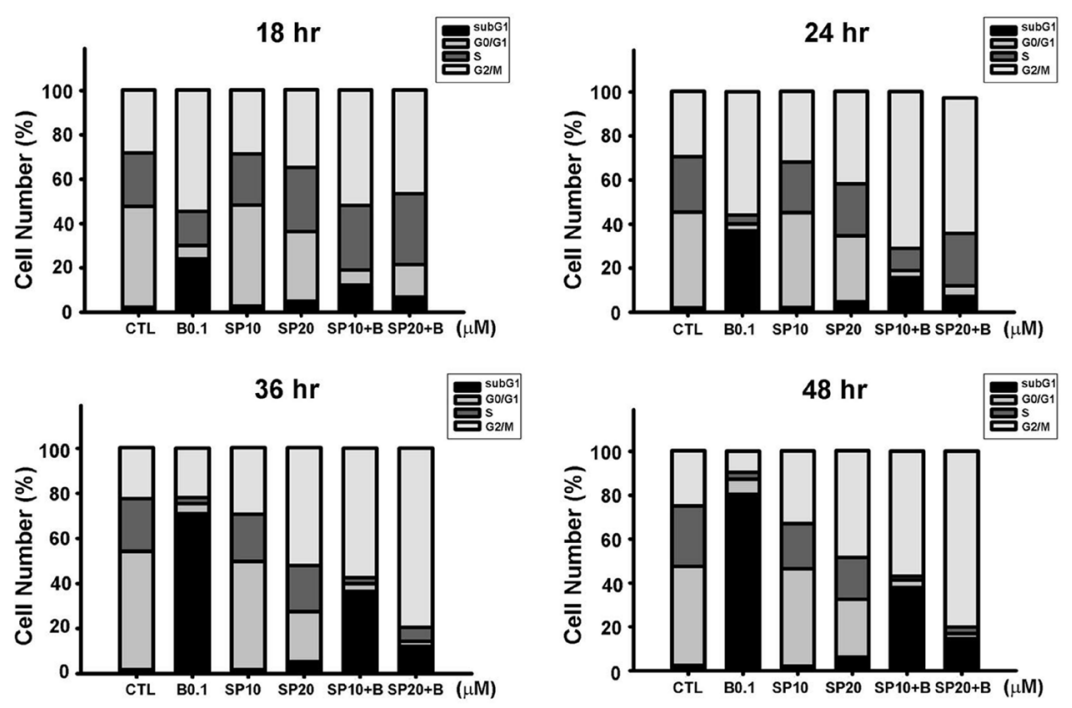

C

D
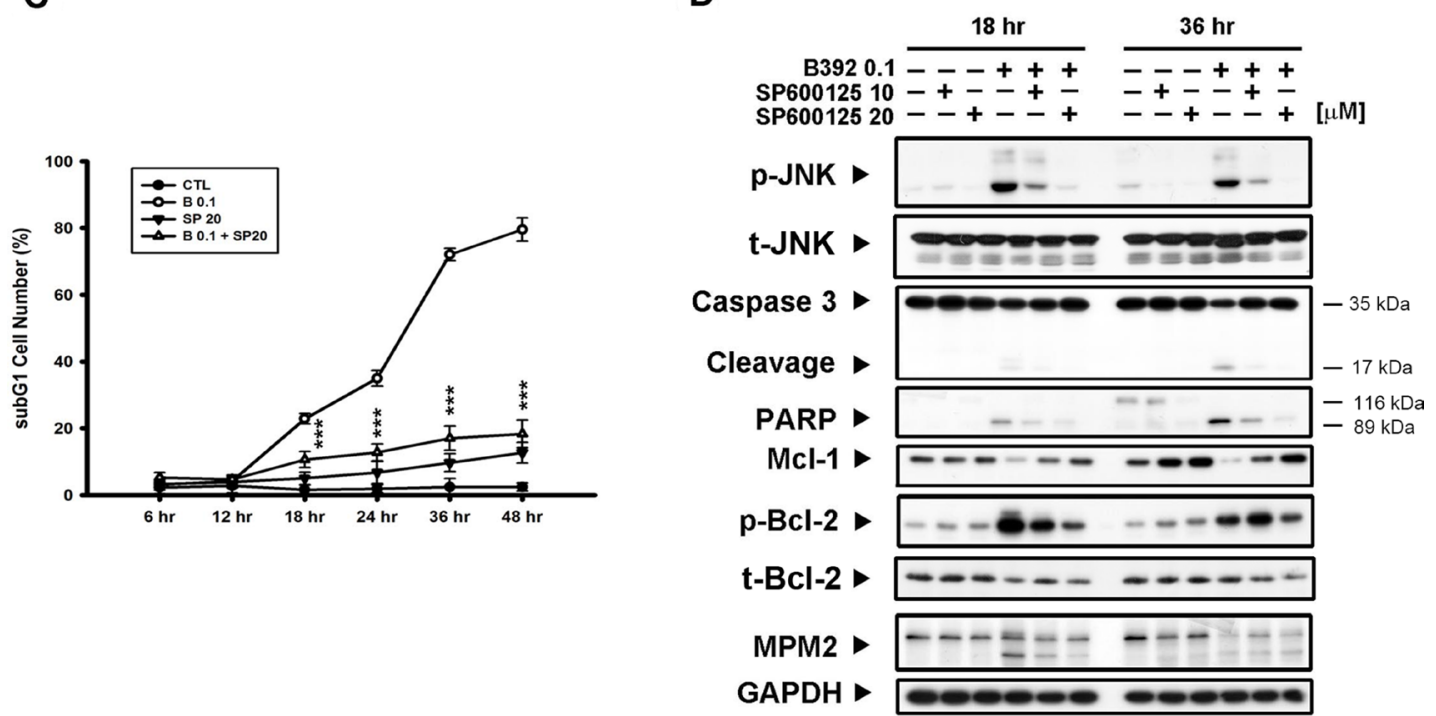

Figure 5: JNK activation was involved in B392-caused cell apoptosis. (A) HL60 cells were treated with vehicle (0.1\% DMSO) or B392 $(0.1 \mu \mathrm{M})$ for time course. The cells were harvested for detection of indicated proteins by western blot analysis. (B) HL60 cells were exposed to B392 $(0.1 \mu \mathrm{M})$ in the absence or presence of SP600125 $(10,20 \mu \mathrm{M})$ for 18, 24, 36 and 48 hours. Cell cycle distribution was analyzed by flow cytometry as well as determining $(\mathbf{C})$ the percentage of subG1 cell number. $(* * * P<0.001)$ (D) The expression of indicated proteins was determined after treatment of HL60 with $0.1 \mu \mathrm{M}$ B392 in the absence or presence of SP600125 $(10,20 \mu \mathrm{M})$ pretreatment for 30 min. SP: SP600126, p-JNK inhibitor. 
p-gp in NCI/ADR-RES cell line. The results indicate that rhodamine-123, a substrate of p-gp, was effluxed, and this phenomenon was inhibited by co-treatment with verapamil, a p-gp inhibitor, as observed by the dye retention in the cells. In contrast, the efflux of rhodamine did not decrease even after co-incubation with a high concentration of B392 $(10 \mu \mathrm{M})$, implying that the intake of B392 was not interfered by $\mathrm{p}$-gp expression and function in tumor cells (Figure 7B). Our data suggests that B392 is a strong microtubule binding agents but not a p-gp substrate.
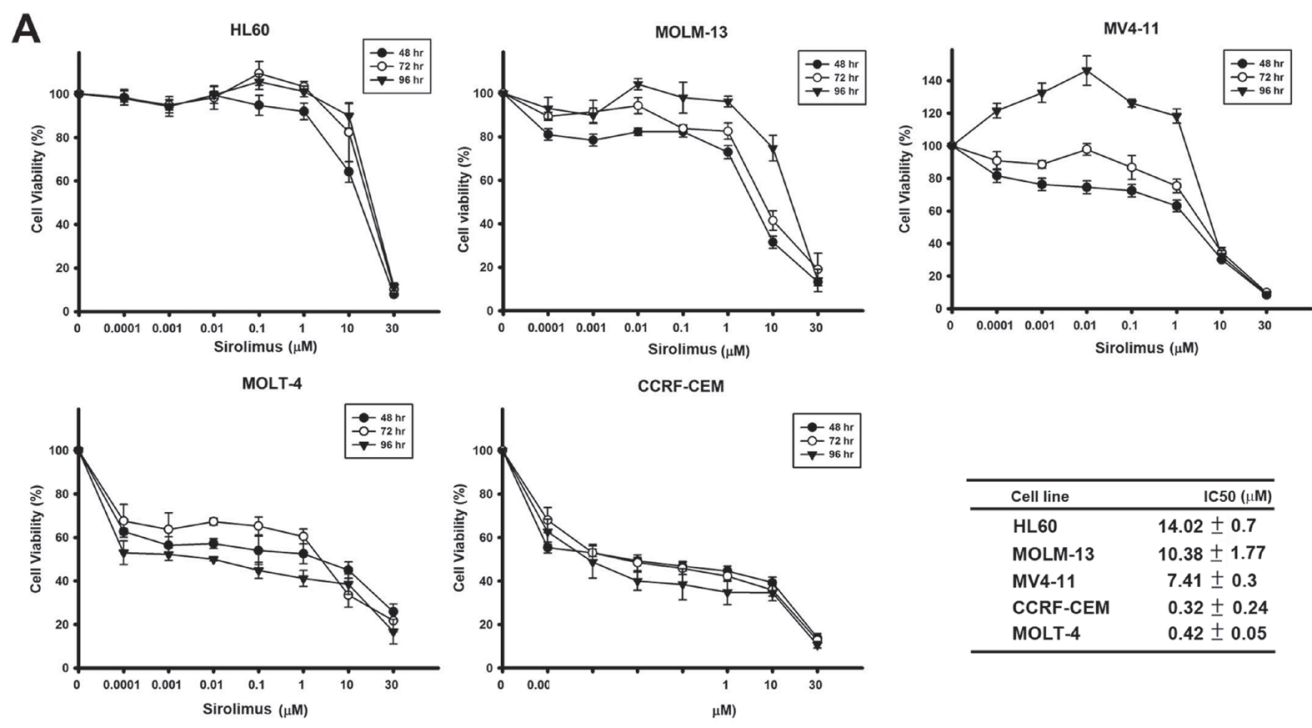

\begin{tabular}{lc}
\hline Cell line & IC50 $(\mu \mathrm{M})$ \\
\hline HL60 & $14.02 \pm 0.7$ \\
MOLM-13 & $10.38 \pm 1.77$ \\
MV4-11 & $7.41 \pm 0.3$ \\
CCRF-CEM & $0.32 \pm 0.24$ \\
MOLT-4 & $0.42 \pm 0.05$ \\
\hline
\end{tabular}

B
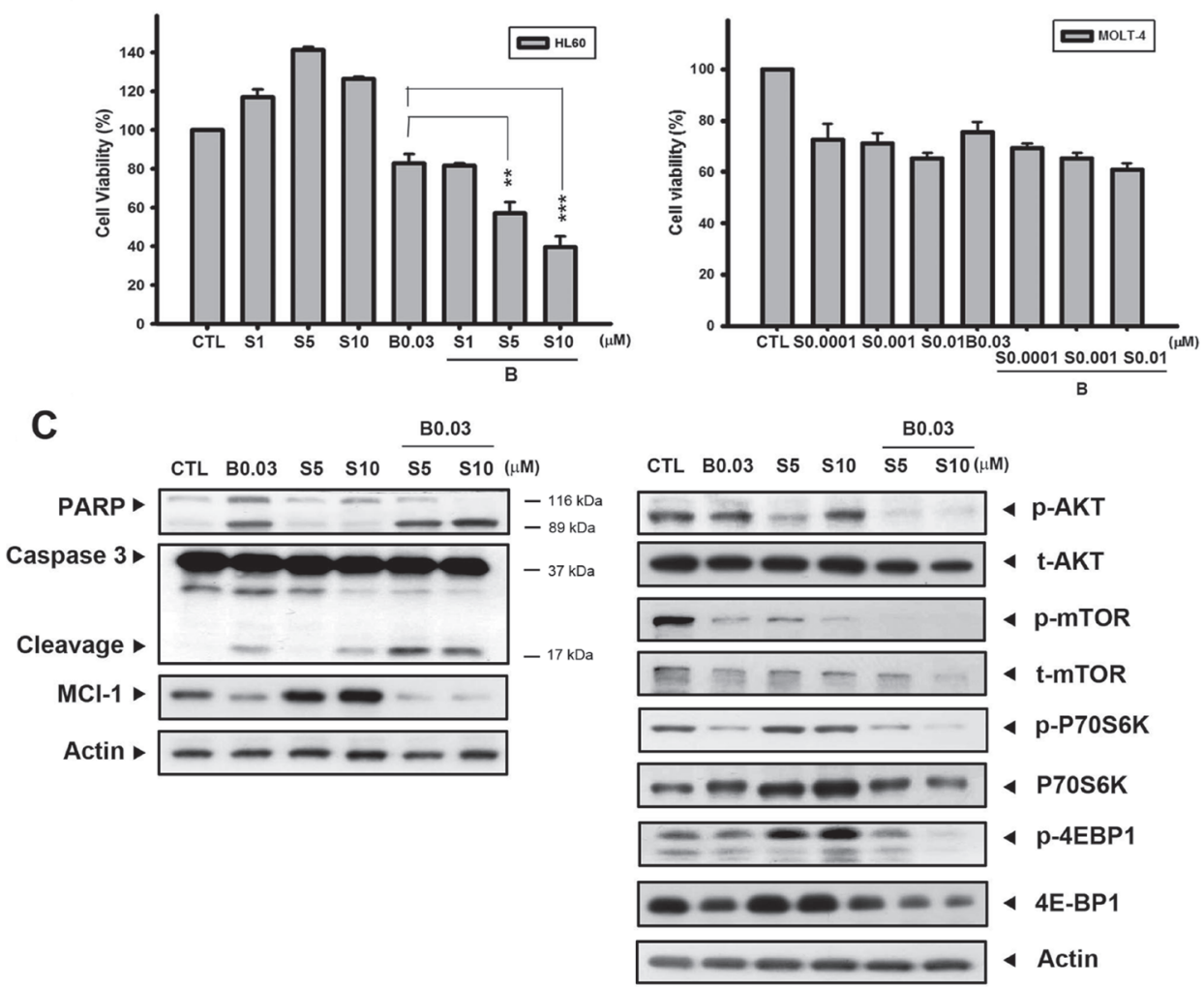

Figure 6: B392 sensitized sirolimus anticancer activity in sirolimus-resistant cell line. (A) Acute myeloid leukemia cell lines (HL60, MV4-11, MOLM-13) and lymphoblastic cell lines (MOLT-4, CCRF-CEM) were treated with indicated concentration of sirolimus for 48, 72, $96 \mathrm{~h}$. The cell viability was determined by MTT assay. The right table summarizes the IC50 of sirolimus at $72 \mathrm{~h}$. IC50 values were calculated by sigmoidal dose-response equation and expressed as mean plus minus SD. (B) The cell viability of B392 combined with sirolimus at 72 h. (C) The expression of caspase 3, PARP, p-AKT, t-AKT, p-mTOR, t-mTOR, p-P70S6K, P70S6K, p-4EBP1, 4EBP, Mcl-1 and actin was determined after $0.03 \mu \mathrm{M}$ B392 combination with $5 \mu \mathrm{M}$ or $10 \mu \mathrm{M}$ sirolimus for $72 \mathrm{~h}$. S: sirolimus $* * P<0.01, * * * P<0.001$. 


\section{DISCUSSION}

In this study, we reported a novel oral quinoline derivative, B392 as a potential drug candidate for anti-leukemia and multiple drug resistant cells. B392 dramatically inhibited leukemic cells survival; however, it had less cytotoxicity on normal cells in vitro and in vivo. The further evidences demonstrated that B392 is a depolymerizing MTA, which caused mitotic arrest. JNK played an essential mediator in B392-induced cells apoptosis through mitochondria disruption which ultimately leading to caspases activation. In addition, in sirolimus-resistant leukemic cells, B392 enhanced the cytotoxic effect of sirolimus; and the more importantly, it is not a substrate of $\mathrm{p}$-gp.

Understanding the mechanisms of drug resistance to approved MTA, as well as their drawbacks in clinical therapy, is extremely important for the development of a promising and potent compound that targets microtubules. The main cause of MTA drug resistance in cancers is alteration of tubulin and overexpression of members of the $\mathrm{ABC}$ family, of which p-gp is the best known [8]. Several lines of evidence have revealed that vinca alkaloids and taxanes are pumped out by the membrane transporter $\mathrm{p}$-gp, the product of multidrug resistance $(M D R)$ gene and multidrug resistance-associated protein (MRP), thereby decreasing their intracellular concentrations and efficacy [26-28]. Therefore, after we demonstrated that B392 is indeed a microtubule destabilizing agent, as manifested by the result of our in vitro tubulin binding assay (Figure 3A), we also evaluated the susceptibility of B392 to p-gp in a p-gp-overexpressed NCI/ADRRES cell line. We showed that NCI/ADR-RES cell was more sensitive to B392 than to vincristine or paclitaxel (Figure 7A) and the efflux of rhodamine did not decrease after co-incubation with a B392 (Figure 7B), implying that B392 might not be excluded by membrane transporter p-gp. Furthermore, most FDA-approved MTA for cancer treatment require parenteral administration; however, B392 was particularly designed for oral administration.
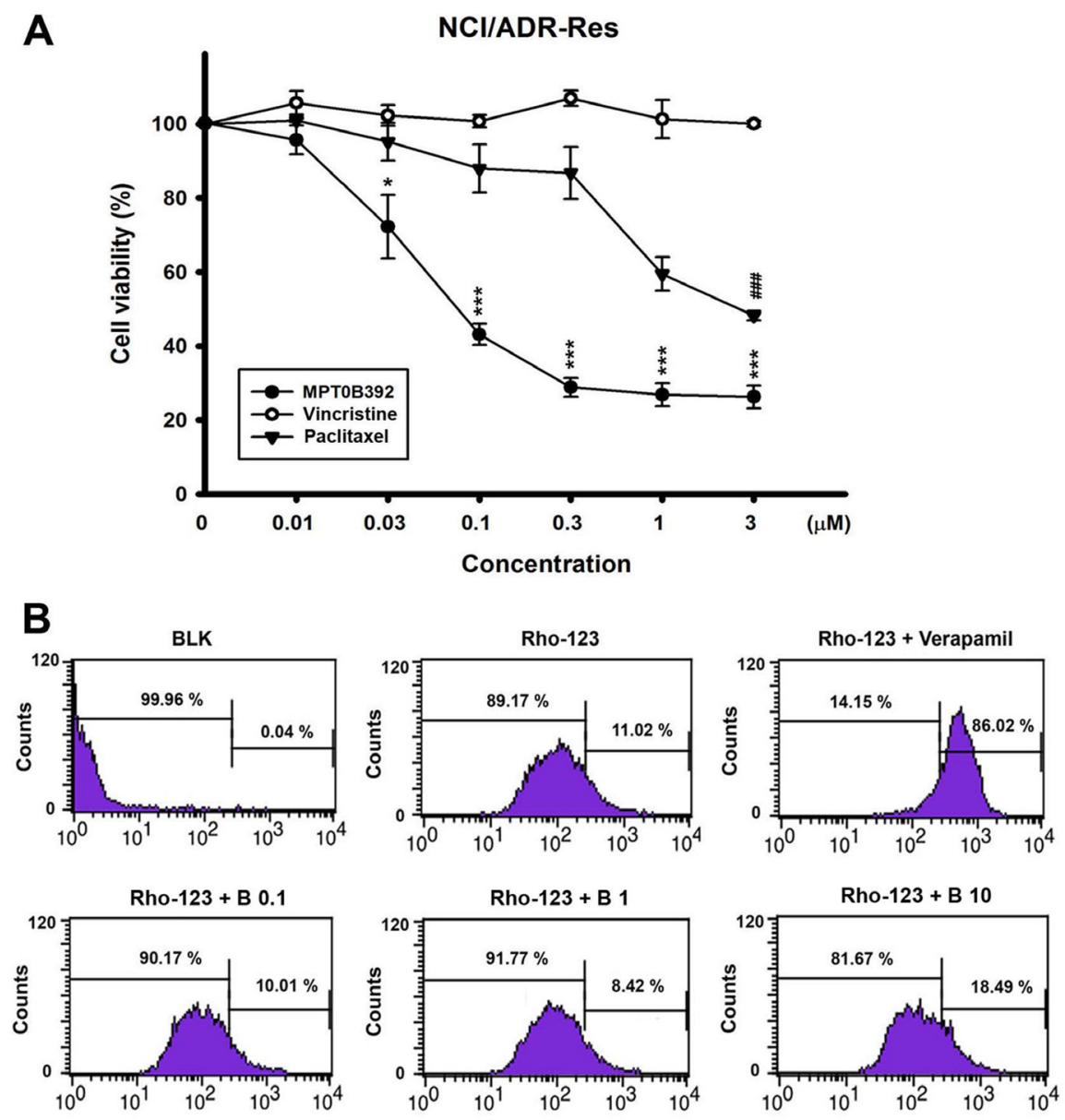

Figure 7: The cell viability of B392 on NCI/ADR-RES cell line and the effect on p-gp activity. (A) NCI/ADR-RES cells were treated with indicated concentrations of B392, vincristine or paclitaxel for $48 \mathrm{~h}$. The cell viability was determined by MTT assay. $\left({ }^{*} P<0.05,{ }^{*} P<0.01,{ }^{* * *} P<0.001\right)(\mathbf{B}) \mathrm{NCI} / \mathrm{ADR}-\mathrm{RES}$ cells were treated with or without indicated agents (Verapamil, $50 \mu \mathrm{M}$; B392, $0.1,1,10 \mu \mathrm{M}$ ) for $1 \mathrm{~h}$. After treatment with indicated drugs for $30 \mathrm{~min}, 10 \mu \mathrm{M}$ Rhodiamine-123 was added and incubation for $30 \mathrm{~min}$ at $37^{\circ} \mathrm{C}$. The signal of fluorescence was detected by flow cytometry. BLK, blank; Rho-123, Rhodiamine 123; B, B392. 
The xenograft animal model demonstrated that antitumor efficacy after oral administration of B392 (Figure 2). Thus, B392 can be considered a potential and promising MTA for the treatment of leukemia.

We also performed a molecular docking analysis to identify the binding site of MPT0B392 on tubulin (Supplementary Figure 4). Tubulin has three main binding sites, namely colchicine, vincristine, and paclitaxel binding sites [29]. B392 was docked into each binding site using an in-house molecular docking tool, iGEMDOCK [30]. The docking results show that MPT0B392 occupied the colchicine binding site and exhibited the best docking score. In addition, the binding mode of B392 was similar to that of colchicine (Supplementary Figure 4). Both compounds contain the same functional group, 1,2,3-trimethoxybenzene, which is sandwiched by two hydrophobic residues L248 and L255 and forms stable van der Waals interactions with the residues. These observations suggest that B392 binds to the colchicine binding site and possesses a similar inhibition mechanism with colchicine.

Cell cycle progression is precisely regulated by cyclin and cyclin kinase complexes [31]. The activation of the cyclin $\mathrm{B} 1 / \mathrm{Cdk} 1$ complex in the nucleus is responsible for entry into mitosis from the G2 phase. The observed upregulation of cyclin B1, decrease of phosphorylated Cdc2 at Tyr-15, and the phosphorylation of MPM2 demonstrated that B392 induced mitotic arrest and not G2 phase arrest (Figure 1D, 3C). In mitosis, if a chromosome attaches incorrectly to microtubule, the metaphase checkpoint (also called spindle assembly checkpoint, SAC) would be activated to elicit signal cascades to inhibit the APC, which causes cyclin B1 degradation and results in cells exiting mitosis [32]. In the present study, we found that after treatment with B392, the expression of Aurora A and Aurora B increased, and their downstream target H3S10 was phosphorylated, implying that B392 disrupted microtubule formation and might lead to SAC activation (Figure 3C). However, not every cancer cell with prolonged mitosis undergo apoptosis [33]. Antiapoptotic mitochondrial proteins, Bcl-2, $\mathrm{Mcl}-1$, and $\mathrm{Bcl}-$ $\mathrm{xL}$, have been shown to be critical factors involved in the MTA-induced apoptosis pathway [34]. Knockdown of Mcl-1 can sensitize cells to spindle poison treatment [35] and overexpression of phospho-defective mutant Bcl-2 can block mitotic death [36]. In the present study, we found that B392 induced Bcl-2 phosphorylation and Mcl1 decrease, which contributed to mitochondrial membrane potential loss, and caspase activation, indicating that B392 has actual cytotoxic abilities and does not merely increase cellular progression through mitosis.

Three MAPKs, ERK, JNK, and p38, have been found to be stress inducible in maintenance of cell functions. ERK was initially associated with cell proliferation and survival, whereas JNK and p38 were considered stress-inducible with effects on apoptosis.
However, the mechanisms underlying MAPK regulation of apoptosis are complex and controversial, and might depend on cell type and drugs $[23,37]$. Bcl-2, phosphorylated and inactivated by the JNK pathway, is normally activated in G2/M phase [38]. Therefore, we investigated to determine the specific MAPK that contributes to B392-induced apoptosis. Figure 5 shows that JNK inactivation can reverse B392-induced phosphorylation of Bcl2, decrease in Mcl-1, cell cycle distribution, and PARP and cleavage caspase 3 . These imply that B392-induced JNK activation triggers the apoptotic pathway in leukemic cell lines.

Because mTOR signaling has proved to be crucial to cell proliferation and survival in hematological malignancies, mTOR inhibitors are being investigated in a myriad of preclinical and clinical trials [39]. However, the results of clinical studies suggest that some cancers have intrinsic resistance against these agents, while some have acquired resistance $[40,41]$. According to our results, AML cell lines (HL60, MOLM-13, and MV4-11) show relative resistant to sirolimus when compared with ALL cell lines (MOLT-4 and CCRF-CEM) (Figure 6A). The synergism of B392 and sirolimus co-treatment was only observed in AML cell line (Figure 6B; Supplementary Table 1). It was reported that almost all AML samples have been observed to contain activated mTOR1, which is independent of PI3K/AKT [25]. Inhibition of mTOR1 by sirolimus would overactivate $\mathrm{PI} 3 \mathrm{~K} / \mathrm{AKT}$, thus producing AML cell resistance to sirolimus. It was also noted that downregulation of Mcl-1, a prosurvival member of the Bcl-2 family, can overcome resistance to sirolimus [42]. p-AKT and Mcl-1 expression decreased dramatically after B392 and sirolimus co-treatment (Figure 6C). Therefore, we hypothesized that the mechanism underlying this synergistic combination in AML cells might involve the inhibition of multiple pathways. Crazzolara. et al demonstrated that everolimus-vincristine co-treatment prolonged the survival of mice engrafted with ALL cells [43]. However, the combination of sirolimus and B392 had no effect on the ALL cell line, MOLT-4, in our in vitro study. We suggested that there might be more complicated mechanisms or factors influenced by the microenvironment that lead to this diversity.

Acute myeloid leukemia or acute lymphoblastic leukemia is a kind of high and poor risk leukemia, containing many subtypes based on distinct and complicated cytogenetic or molecular abnormalities, in contrast to chronic leukemia. Although conventional microtubule targeting drugs are regarded as an outdated chemotherapy, it cannot be denied that they can still have an impact on current anticancer therapy, as long as their deficiencies are improved. In the present study, we developed a novel oral quinoline derivative B392, that has an ability to inhibit tubulin polymerization and induce leukemic cell apoptosis though JNK activation. It is also less susceptible to p-gp activity, and enhances the cytotoxicity of sirolimus in sirolimus-resistant cells. Thus, 
B392 is considered a potential drug for the treatment of acute leukemia and multiple drug resistant cancers.

\section{MATERIALS AND METHODS}

\section{Cell lines and biochemical regents}

HL60 (acute promyelocytic leukemia), MOLT-4 (acute lymphoblastic leukemia) and CCRF-CEM (acute lymphoblastic leukemia), BEAS (normal human bronchial epithelium) and HUVEC (Human umbilical vein endothelial cell) were purchased from BCRC (Bioresource Collection and Research Centre, Taiwan); NCI/ADR-RES (National Cancer Institute/Adriamycin-Resistant, human ovarian carcinoma cell line) was obtained from the DTP Human Tumor Cell Line Screen; MV4-11(acute myeloid leukemia cell) and MOLM-13 (acute myeloid leukemia cell) were kindly gifted from National Health Research Institutes. HL60, MOLT-4, CCRF-CEM, BEAS, MV411, MOLM-13 and NCI/ADR-RES were maintained in RPMI-1640 medium (Invitrogen) supplemented with 10\% FBS. HUVEC were grown in endothelial cell medium (ECM) (ScienCell Research Laboratory, Carlsbad, CA) supplemented with $20 \%$ FBS. All cell lines were incubated in $5 \% \mathrm{CO}_{2}$ at $37^{\circ} \mathrm{C}$. B392 was synthetized from Prof. JingPing Liou (Taipei Medical University), and the purity is over 98\%. Paclitaxel and vincristine were purchased from Sigma (St. Louis, MO). All of the above drugs were reconstituted in dimethysulfoxide (DMSO).

\section{Cell viability}

The MTT (3- (4,5-cimethylthiazol-2-yl)-2,5-diphenyl tetrazolium bromide) assay was used to determine cell viability. The mitochondrial dehydrogenase of viable cells reduced 3-(4,5-dimethylthiazol-2-yl)-2,5-diphenyltetrazolium bromide, MTT (yellow) to insoluble formazan dyes (purple). Cells were seeded in 24 -well $\left(4 \times 10^{5}\right.$ cells/well $)$ and then treated with B392 in 10\% FBS-culture medium for 24 and $48 \mathrm{~h} .100 \mu \mathrm{L} \mathrm{mg} / \mathrm{mL}$ MTT solution $(0.5 \mathrm{mg} / \mathrm{mL}$ in PBS) was added to the 24 -well and incubated for $1 \mathrm{~h}$ at $37^{\circ} \mathrm{C}$. The dyes were solubilized in the extraction buffer $(0.1 \mathrm{M}$ sodium acetate buffer, $100 \mathrm{~mL} /$ well). Finally, the absorbance (550 $\mathrm{nm}$ ) was measured by spectrophotometer.

\section{Cell cycle analysis}

Cells were seeded in six-well plates $\left(8 \times 10^{5} /\right.$ well $)$ and treated with the drugs for the indicated time. Cells were collected, washed with PBS and fixed in $70 \% \mathrm{EtOH}$ at $-20^{\circ} \mathrm{C}$ for at least $30 \mathrm{~min}$. Then cells were washed with PBS, treated with DNA extraction $\left(0.2 \mathrm{M} \mathrm{Na}_{2} \mathrm{HPO}_{4}^{-}\right.$ $0.1 \mathrm{M}$ citritic buffer, $\mathrm{pH} 7.8$ ) for $20 \mathrm{~min}$ and finally stained with propidium iodide (PI) solution $(0.1 \%$ Triton X-100, RNAase A and PI) for $20 \mathrm{~min}$. DNA contents were analyzed by flow cytometry using FACS Calibur (BD Biosciences).

\section{In vitro tubulin polymerization assay}

Tubulin polymerization assay was conducted by using CytoDYNAMIX screen 03 kit (Cytoskeleton Inc., Denver, CO, USA). All steps were followed by manufacturer's protocol. Before preparing tubulin polymerization (TP) buffer, a 96 well-plate was pre-warmed in the Spectrophotometer at $37^{\circ} \mathrm{C}$. TP buffer (including General Tubulin Buffer, Tubulin Glycerol Buffer and GTP), $85 \mu \mathrm{L} /$ well and the test drugs $(2 \mu \mathrm{L} /$ well $)$ were added to the prewarmed 96-well plate, respectively. Here, DMSO was used for control, paclitaxel and vincristine for positive controls. Tubulin proteins were immediately added to the mixture (30 $\mu \mathrm{L} /$ well). The absorbance, $340 \mathrm{~nm}$, were recorded every $1 \mathrm{~min}$ for $30 \mathrm{~min}$ at $37^{\circ} \mathrm{C}$ by ELISA reader (SpectraMAX Plus; Molecular Devices Inc., Sunnyvale, CA, USA).

\section{Immunofluorescence}

Cells were seeded in round slide glass, pre-coated with poly-L-lysine, and treated with drugs for $24 \mathrm{~h}$. Cells were fixed with $4 \%$ paraformaldehyde, permeabilized with $1 \%$ Triton X-100, blocked with 5\% BSA and then incubated with $\alpha$-tubulin primary antibody (Sigma-Aldrich, St. Louis, MO) overnight. In the next day, cells were washed with PBS and probed with appropriate secondary antibody for $1 \mathrm{~h}$ at RT (room temperature). Finally, cells were stained with mounting gel which contains DAPI then sealed with nail oil. Images were captured with the ZEISS, LSM 510 META confocal microscope.

\section{Tumor xenograft models}

To evaluate in vivo antitumor activity of B392, MOLT-4 or HL60 cells $\left(10^{7} / \mathrm{mice}\right)$ were injected into severe combined immunodeficient (SCID) mice subcutaneously. The following experiments were referenced by our published paper [18]. Mice were treated with indicated dosage of B392 and vincristine orally or intraperitoneally, when the average tumor size reached $100 \mathrm{~mm}^{3}$. The in vivo solvents of B392 and vincristine are $1 \% \mathrm{CMC}$ (carboxymethyl cellulose) with $0.1 \%$ Tween 80 and 50\% Cremophor EL with 50\% DMSO, respectively. Body weights and tumor sizes were measured twice a week. The animal studies terminated when average size of the tumor was greater than $2,500 \mathrm{~mm}^{3}$. Tumor size was measured by caliper measurement ( $\mathrm{mm}$ ) and ellipsoid sphere formula ( $\mathrm{LW}^{2} / 2$, L: length; W: width). All procedures followed ethical standards and have been approved by National Taiwan University Animal Use and Management Committee (IACUC number: 20110303).

\section{Immunohistochemical staining}

Tumor tissues were resected, immersed in formaldehyde, embedded in paraffin and sectioned. The detailed protocols were as described [44]. The sectioned 
slides were stained with the primary antibody cleavage caspase 3 or hematoxylin and eosin staining. HP-polymer conjugated secondary antibody (SuperPicture Polymer Detection kit) was used and then sectioned slides were stained with DAB Chomogen for $5 \mathrm{~min}$. Mayer's Hematoxylin solution was used for counterstaining. Other sectioned slides in the same tissues were stained with hematoxylin and eosin (H\&E), the color of nuclei was blue and of cytoplasm was pink.

\section{Western blot analysis}

Cells were treated with drugs for indicated time and collected, washed with PBS. Pellets were lysed with RIPA (radioimmunoprecipitation assay) buffer containing protease and phosphatase inhibitors and under sonication. The supernatants were harvested. Protein concentrations were determined by BCA kit (Thermo Fisher scientific, Waltham, MA). The equal amounts of protein were loaded onto a sodium dodecyl sulfate-polyacrylamide (SDSPAGE) gel then transferred to polyvinylidene difluorid (PVDF) membrane. The membranes were blocked for $1 \mathrm{~h}$ with $5 \%$ non-fat milk and probed with the primary antibodies of interest overnight at $4^{\circ} \mathrm{C}$. The next day membranes were washed with TBST (Tris Buffered Saline with Tween ${ }^{\circledR} 20$ ) and subsequently incubated with appropriate horseradish peroxidase-conjugated secondary antibodies $1 \mathrm{~h}$ at RT. The antibody used in this study as follows : Cdc2 (pY15), Aurora B, caspase-8, caspase-9, p-mTOR, t-mTOR, p-AKT, t-AKT, p-P70S6K, P70S6K, p-4EBP, t-4EBP, p-JNK, t-JNK, p-P38, t-P38, p-ERK, t-ERK and internal controls, GAPDH and actin, were all purchased from Cell Signaling Technologies (Beverly, MA); Cyclin B, Cdc25C, Cdc2, PARP, Mcl-1, Bcl-2, pBcl-2, Bcl-xl and secondary antibodies were purchased from Santa Cruz (Santa Cruz, CA, USA); MPM2 (pSer/Th), H3 (pS10) were purchased from Upstate Biotechnology (Lake Placid, NY, USA); caspase 7 and caspase 3 were purchased from BD Bioscience (San Jos, CS, USA) and Imgenex (San Diego, CA, USA), respectively.

\section{Mitochondrial membrane potential loss}

Rhodamine-123, a cell-permeant and green fluorescent dye with negative charged which can selectively bind to mitochondria membrane potential, was usually used to monitor mitochondrial membrane potential. Before cells were harvested, Rhodamine-123 was added then incubated for $30 \mathrm{~min}$ at $37^{\circ} \mathrm{C}$. The results were analyzed by FACScan Flow Cytometer and CellQuest software (Bectman Dickinson)

\section{P-gp activity assay}

Cells were treated with or without the indicated agents for $30 \mathrm{~min}$ and then co-treated with $10 \mu \mathrm{M}$
Rhodamine- 123 for $30 \mathrm{~min}$ at $37^{\circ} \mathrm{C}$. Cells were trpsinized, washed with PBS and analyzed by flow cytometry (FACS Calibur, BD Biosciences).

\section{Statistical analysis}

All experimental data were repeated at least three times and expressed as means $( \pm$ SD). Statistical analysis was evaluated by student $t$-test, which was calculated to compare the mean of each group with that of the control group. $P$-values $<0.05$ were represented statistical significance $(* P<0.05, * * P<0.01, * * * P<0.001)$.

\section{Ethics approval and consent to participate}

All in vivo procedures followed ethical standards and have been approved by National Taiwan University Animal Use and Management Committee.

\section{Consent for publication}

All authors has read and approved the final manuscript.

\section{Abbreviations}

MPT0B392: B392; MTA: microtubule-targeting agent; JNK: c-Jun N-terminal kinase; p-gp: p-glycoprotein; SAC: spindle assembly checkpoint; APC anaphasepromoting complex; ABC: ATP-binding cassette.

\section{ACKNOWLEDGMENTS}

We specially thank National Health Research Institutes of Taiwan for MV4-11 and MOLM-13 cell lines as well as The Third Core Lab, Branch Office of Research and Development, National Taiwan University College of Medicine for supporting the technique of immunofluorescence.

\section{CONFLICTS OF INTEREST}

There are no competing interests in this article.

\section{FUNDING}

This research was supported by the Ministry of Science and Technology, Taiwan (MOST103-2320-B-002008-MY3).

\section{Authors' contributions}

MWC constructed an idea and hypothesis for research and manuscript; HLH and WCHF took responsibility in the construction of the whole or body 
of the manuscript; $\mathrm{KCH}$ performed the docking analysis; YML provided chemical materials and reagents; YWW and CFL participated in biological materials; YLC carried out the animal experiments; MJL and HYL planned methodology to reach the conclusion; JPL and CMT took responsibility in the construction of the manuscript; and CRY supervised the course of the article and took the responsibility

\section{REFERENCES}

1. Rose-Inman H, Kuehl D. Acute leukemia. Emerg Med Clin North Am. 2014; 32:579-96. doi: 10.1016/j. emc.2014.04.004.

2. Douer D. Efficacy and Safety of Vincristine Sulfate Liposome Injection in the Treatment of Adult Acute Lymphocytic Leukemia. Oncologist. 2016; 21:840-7. doi: 10.1634/theoncologist.2015-0391.

3. Al Ustwani O, Gupta N, Bakhribah H, Griffiths E, Wang E, Wetzler M. Clinical updates in adult acute lymphoblastic leukemia. Crit Rev Oncol Hematol. 2016; 99:189-99. doi: 10.1016/j.critrevonc.2015.12.007.

4. Paul S, Kantarjian H, Jabbour EJ. Adult Acute Lymphoblastic Leukemia. Mayo Clin Proc. 2016; 91:1645-66. doi: 10.1016/j.mayocp.2016.09.010

5. Dumontet C, Jordan MA. Microtubule-binding agents: a dynamic field of cancer therapeutics. Nat Rev Drug Discov. 2010; 9:790-803. doi: 10.1038/nrd3253.

6. Liu YM, Chen HL, Lee HY, Liou JP. Tubulin inhibitors: a patent review. Expert Opin Ther Pat. 2014; 24:69-88. doi: 10.1517/13543776.2014.859247.

7. Holohan C, Van Schaeybroeck S, Longley DB, Johnston PG. Cancer drug resistance: an evolving paradigm. Nat Rev Cancer. 2013; 13:714-26. doi: 10.1038/nrc3599.

8. Fojo AT, Menefee M. Microtubule targeting agents: basic mechanisms of multidrug resistance (MDR). Semin Oncol. 2005; 32:S3-8. doi: 10.1053/j.seminoncol.2005.09.010.

9. Petroulakis E, Mamane Y, Le Bacquer O, Shahbazian D, Sonenberg N. mTOR signaling: implications for cancer and anticancer therapy. British Journal of Cancer. 2006; 94:195-9. doi: 10.1038/sj.bjc.6602902.

10. Chapuis N, Tamburini J, Green AS, Willems L, Bardet V, Park S, Lacombe C, Mayeux P, Bouscary D. Perspectives on inhibiting mTOR as a future treatment strategy for hematological malignancies. Leukemia. 2010; 24:1686-99. doi: 10.1038/leu.2010.170.

11. Faivre S, Kroemer G, Raymond E. Current development of mTOR inhibitors as anticancer agents. Nat Rev Drug Discov. 2006; 5:671-88. doi: 10.1038/nrd2062.

12. Kategaonkar AH, Pokalwar RU, Sonar SS, Gawali VU, Shingate BB, Shingare MS. Synthesis, in vitro antibacterial and antifungal evaluations of new alphahydroxyphosphonate and new alpha-acetoxyphosphonate derivatives of tetrazolo [1, 5-a] quinoline. Eur J Med Chem. 2010; 45:1128-32. doi: 10.1016/j.ejmech.2009.12.013.
13. Joshi AA, Narkhede SS, Viswanathan CL. Design, synthesis and evaluation of 5-substituted amino-2,4-diamino-8chloropyrimido-[4,5-b]quinolines as novel antimalarials. Bioorg Med Chem Lett. 2005; 15:73-6. doi: 10.1016/j. bmcl.2004.10.037.

14. Milner E, McCalmont W, Bhonsle J, Caridha D, Carroll D, Gardner S, Gerena L, Gettayacamin M, Lanteri C, Luong T, Melendez V, Moon J, Roncal N, et al. Structure-activity relationships amongst 4-position quinoline methanol antimalarials that inhibit the growth of drug sensitive and resistant strains of Plasmodium falciparum. Bioorg Med Chem Lett. 2010; 20:1347-51. doi: 10.1016/j. bmcl.2010.01.001.

15. Gopaul K, Shintre SA, Koorbanally NA. A Review on the Synthesis and Anti-Cancer Activity of 2-Substituted Quinolines. Anticancer Agents Med Chem. 2014.

16. Rostom SA. Synthesis and in vitro antitumor evaluation of some indeno[1,2-c]pyrazol(in)es substituted with sulfonamide, sulfonylurea(-thiourea) pharmacophores, and some derived thiazole ring systems. Bioorg Med Chem. 2006; 14:6475-85. doi: 10.1016/j.bmc.2006.06.020.

17. Lo WF, Chou YW, Tseng CH, Shiu YH, Chen YW, Yang SC, Chen YL, Lin MF, Tzeng CC. Discovery of Novel N-Alkyl 4-Anilinofuro[2,3-b]Quinoline Derivatives (CIL-102 Derivatives) Against Castration-Resistant Human Prostate Cancers. Anticancer Agents Med Chem. 2015.

18. Castedo M, Perfettini JL, Roumier T, Andreau K, Medema R, Kroemer G. Cell death by mitotic catastrophe: a molecular definition. Oncogene. 2004; 23:2825-37. doi: 10.1038/sj.onc. 1207528.

19. Keen N, Taylor S. Mitotic drivers - inhibitors of the Aurora B Kinase. Cancer Metastasis Rev. 2009; 28:185-95. doi: 10.1007/s10555-009-9184-9.

20. Kim R, Emi M, Tanabe K. Role of mitochondria as the gardens of cell death. Cancer Chemotherapy and Pharmacology. 2006; 57:545-53. doi: 10.1007/s00280-0050111-7.

21. Bae J, Leo CP, Hsu SY, Hsueh AJ. MCL-1S, a splicing variant of the antiapoptotic BCL-2 family member MCL1 , encodes a proapoptotic protein possessing only the $\mathrm{BH} 3$ domain. J Biol Chem. 2000; 275:25255-61. doi: 10.1074/ jbc.M909826199.

22. Bacus SS, Gudkov AV, Lowe M, Lyass L, Yung Y, Komarov AP, Keyomarsi K, Yarden Y, Seger R. Taxolinduced apoptosis depends on MAP kinase pathways (ERK and p38) and is independent of p53. Oncogene. 2001; 20:147-55. doi: 10.1038/sj.onc.1204062.

23. Stone AA, Chambers TC. Microtubule inhibitors elicit differential effects on MAP kinase (JNK, ERK, and p38) signaling pathways in human KB-3 carcinoma cells. Exp Cell Res. 2000; 254:110-9. doi: 10.1006/excr.1999.4731.

24. Vu C, Fruman DA. Target of Rapamycin Signaling in Leukemia and Lymphoma. Clinical Cancer Research. 2010; 16:5374-80. doi: 10.1158/1078-0432.ccr-10-0480. 
25. Park S, Chapuis N, Tamburini J, Bardet V, CornilletLefebvre P, Willems L, Green A, Mayeux P, Lacombe C, Bouscary D. Role of the PI3K/AKT and mTOR signaling pathways in acute myeloid leukemia. Haematologica. 2010.

26. Breuninger LM, Paul S, Gaughan K, Miki T, Chan A, Aaronson SA, Kruh GD. Expression of multidrug resistance-associated protein in NIH/3T3 cells confers multidrug resistance associated with increased drug efflux and altered intracellular drug distribution. Cancer Res. 1995; 55:5342-7.

27. Bruggemann EP, Currier SJ, Gottesman MM, Pastan I. Characterization of the azidopine and vinblastine binding site of P-glycoprotein. J Biol Chem. 1992; 267:21020-6.

28. Huisman MT, Chhatta AA, van Tellingen O, Beijnen JH, Schinkel AH. MRP2 (ABCC2) transports taxanes and confers paclitaxel resistance and both processes are stimulated by probenecid. Int J Cancer. 2005; 116:824-9. doi: 10.1002/ijc.21013.

29. Jordan MA, Wilson L. Microtubules as a target for anticancer drugs. Nat Rev Cancer. 2004; 4: 253-65. doi: $10.1038 / \mathrm{nrc} 1317$.

30. Hsu KC, Chen YF, Lin SR, Yang JM. iGEMDOCK: a graphical environment of enhancing GEMDOCK using pharmacological interactions and post-screening analysis. BMC Bioinformatics. 2011; 12:S33. doi: 10.1186/14712105-12-s1-s33.

31. Bloom J, Cross FR. Multiple levels of cyclin specificity in cellcycle control. Nat Rev Mol Cell Biol. 2007; 8: 149-60.

32. Kang J, Yu H. Kinase signaling in the spindle checkpoint. J Biol Chem. 2009; 284:15359-63. doi: 10.1074/jbc. R900005200.

33. Matson DR, Stukenberg PT. Spindle poisons and cell fate: a tale of two pathways. Mol Interv. 2011; 11:141-50. doi: 10.1124/mi.11.2.12.

34. Ruvolo PP, Deng X, May WS. Phosphorylation of Bcl2 and regulation of apoptosis. Leukemia. 2001; 15:515-22.

35. Wertz IE, Kusam S, Lam C, Okamoto T, Sandoval W, Anderson DJ, Helgason E, Ernst JA, Eby M, Liu J, Belmont LD, Kaminker JS, O'Rourke KM, et al. Sensitivity to antitubulin chemotherapeutics is regulated by MCL1 and FBW7. Nature. 2011; 471:110-4. doi: 10.1038/nature09779.
36. Eichhorn JM, Sakurikar N, Alford SE, Chu R, Chambers TC. Critical role of anti-apoptotic Bcl-2 protein phosphorylation in mitotic death. Cell Death Dis. 2013; 4:e834. doi: 10.1038/cddis.2013.360.

37. Wada T, Penninger JM. Mitogen-activated protein kinases in apoptosis regulation. Oncogene. 0000; 23:2838-49.

38. Yamamoto K, Ichijo H, Korsmeyer SJ. BCL-2 Is Phosphorylated and Inactivated by an ASK1/Jun N-Terminal Protein Kinase Pathway Normally Activated at G(2)/M. Molecular and Cellular Biology. 1999; 19:8469-78.

39. Teachey DT, Grupp SA, Brown VI. mTOR Inhibitors and Their Potential Role in Therapy in Leukemia and Other Haematologic Malignancies. British journal of haematology. 2009; 145:569-80. doi: 10.1111/j.13652141.2009.07657.x.

40. Kurmasheva RT, Huang S, Houghton PJ. Predicted mechanisms of resistance to mTOR inhibitors. Br J Cancer. 2006; 95:955-60. doi: 10.1038/sj.bjc.6603353.

41. Witzig TE, Geyer SM, Ghobrial I, Inwards DJ, Fonseca R, Kurtin P, Ansell SM, Luyun R, Flynn PJ, Morton RF, Dakhil SR, Gross H, Kaufmann SH. Phase II trial of singleagent temsirolimus (CCI-779) for relapsed mantle cell lymphoma. J Clin Oncol. 2005; 23:5347-56. doi: 10.1200/ jco.2005.13.466.

42. Muller A, Zang C, Chumduri C, Dorken B, Daniel PT, Scholz CW. Concurrent inhibition of PI3K and mTORC1/ mTORC2 overcomes resistance to rapamycin induced apoptosis by down-regulation of Mcl-1 in mantle cell lymphoma. Int J Cancer. 2013; 133:1813-24. doi: 10.1002/ ijc. 28206 .

43. Crazzolara R, Cisterne A, Thien M, Hewson J, Baraz R, Bradstock KF, Bendall LJ. Potentiating effects of RAD001 (Everolimus) on vincristine therapy in childhood acute lymphoblastic leukemia. Blood. 2009; 113:3297-306. doi: 10.1182/blood-2008-02-137752.

44. Chao MW, Chen CH, Chang YL, Teng CM, Pan SL. alpha-Tomatine-mediated anti-cancer activity in vitro and in vivo through cell cycle- and caspase-independent pathways. PLoS One. 2012; 7:e44093. doi:10.1371/journal. pone. 0044093 . 